\title{
Upregulation of CFTR in patients with endometriosis and its involvement in NFKB-uPAR dependent cell migration
}

\author{
Wenqing Huang ${ }^{1,2, *}$, Aihong Jin ${ }^{4, *}$, Jieting Zhang ${ }^{1,2}$, Chaoqun Wang ${ }^{1,2}$, Lai Ling \\ Tsang ${ }^{1,2}$, Zhiming Cai ${ }^{4}$, Xiaping Zhou ${ }^{4}$, Hao Chen ${ }^{1,2}$ and Hsiao Chang Chan ${ }^{1,2,3}$ \\ ${ }^{1}$ Epithelial Cell Biology Research Center, School of Biomedical Sciences, Faculty of Medicine, The Chinese University of Hong \\ Kong, Shatin, PR China \\ ${ }^{2}$ Institute of Biomedical and Pharmaceutical Sciences, Guangdong University of Technology, Guangzhou, PR China \\ ${ }^{3}$ Sichuan University - The Chinese University of Hong Kong Joint Laboratory for Reproductive Medicine, West China Second \\ Hospital, Sichuan University, Chengdu, PR China \\ ${ }^{4}$ Department of Gynecology, The Second People's Hospital of Shenzhen, Shenzhen, PR China \\ *These authors have contributed equally to this work \\ Correspondence to: Hsiao Chang Chan, email: hsiaocchan@cuhk.edu.hk \\ Hao Chen, email: chenhaojob@yahoo.com \\ Keywords: endometriosis, CFTR, NFKB signaling, UPAR, cell migration
}

Received: January 17, $2017 \quad$ Accepted: March 02, $2017 \quad$ Published: March 22, 2017

Copyright: Huang et al. This is an open-access article distributed under the terms of the Creative Commons Attribution License 3.0 (CC BY 3.0), which permits unrestricted use, distribution, and reproduction in any medium, provided the original author and source are credited.

\section{ABSTRACT}

Endometriotic tissues exhibit high migration ability with the underlying mechanisms remain elusive. Our previous studies have demonstrated that cystic fibrosis transmembrane conductance regulator (CFTR) acts as a tumor suppressor regulating cell migration. In the present study, we explored whether CFTR plays a role in the development of human endometriosis. We found that both mRNA and protein expression levels of CFTR and urokinase-type plasminogen activator receptor (UPAR) were significantly increased in ectopic endometrial tissues from patients with endometriosis compared to normal endometrial tissues from women without endometriosis and positively correlated. In human endometrial Ishikawa (ISK) cells, overexpression of CFTR stimulated cell migration with upregulated NFKB p65 and UPAR. Knockdown of CFTR inhibited cell migration. Furthermore, inhibition of NFKB with its inhibitors (curcumin or Bay) significantly reduced the expression of UPAR and cell migration in the CFTR-overexpressing ISK cells. Collectively, the present results suggest that the CFTR-NFKB-UPAR signaling may contribute to the progression of human endometriosis, and indicate potential targets for diagnosis and treatment.

\section{INTRODUCTION}

Endometriosis is a common benign gynecological disorder defined as the presence of endometrial tissue outside the endometrium and myometrium, and affects almost $10 \%$ of women at reproductive age, even 35 $50 \%$ of women with pelvic pain and/or infertility $[1,2]$. Surgery is the most common treatment, but it recurs at a rate of $40 \%$ in 5 years [3]. The ectopic endometrium acquires the ability to invade and attach the peritoneum by degrading extracellular matrix and recruiting nerves/blood vessels into the lesions $[4,5]$. Although endometriosis is a benign disease, the migratory/invasive potential of ectopic endometrial cells is comparable to that of cells from a metastatic cancer [6].

Urokinase type plasminogen activator (uPA) and its receptor (UPAR) are well-documented to be involved in multiple tissue remodeling and cancer metastasis [7, 8]. Plasminogen was activated and converted to plasmin by the binding of UPA and UPAR, initiating pericellular proteolysis and cell migration and contributing to cancer metastasis [9]. Apart from its role in cancers, uPA signaling was also involved in uterine physiology and the initiation of menstruation $[10,11]$. It has been reported that progesterone inhibits the activation of UPA via increase of PAI-1 and uPAR expression in endometrial stromal cells [12]. Of note, 
the expression of UPA and soluble UPAR has been observed to be upregulated in the endometrium of women with endometriosis [13,14], suggesting the involvement of the uPA system in the progression of endometriosis. However, the molecular mechanism regulating uterine UPAR remains unclear although its regulation by NFKB is well-known in many other tissues $[15,16]$.

CFTR is a cAMP-activated $\mathrm{Cl}^{-}$- and $\mathrm{HCO}_{3}^{-}$transporting channel, expressed in epithelial cells of various organs [17]. Mutations of CFTR result in cystic fibrosis (CF), a lethal genetic disease with multi-organ defects, including infertility $[18,19]$. In the female reproductive tract, CFTR is expressed in the vagina, cervix, uterus, fallopian tube and ovary [20-22]. During the estrus cycle, the expression of CFTR in mouse endometrium is upregulated by estrogen [23] and downregulated by progesterone [24]. This cyclic change of CFTR expression pattern is thought to be important for regulating electrolyte transport and uterine fluid environment required for sperm transport, capacitation and embryo implantation [21, 25]. Apart from its channel function, CFTR has also been shown to be involved in multiple cellular processes including cancer development and metastasis [26-28]. Our previous studies have demonstrated that CFTR acts as a tumor/EMT suppressor, which is shown to be downregulated and associated with poor prognosis in prostate cancer [16], breast cancer [26], colon cancer [29] and lung cancer [30]. However, opposite role of CFTR has been observed in the female reproductive tract. A recent study on ovarian cancer found that CFTR level was significantly increased compared to the benign ovarian tumor and normal ovaries and its expression level was significantly associated with advanced FIGO stage [31]. It has also been demonstrated that the expression of CFTR is significantly increased and highly associated with cervical cancer progression, aggressive behaviors and poorer prognosis [32], accompanied by elevated expression of NFkB p65 [33]. Furthermore, our recent study has demonstrated a direct interaction between CFTR and NFKB p65 in human epithelial colorectal adenocarcinoma cells by Co-Immunoprecipitation [34]. Of interest, CFTR has been implicated in the pathogenesis of endometriosis by a proteomic study together with 20 proteins identified [35]. However, quantified expression level of CFTR in human endometriosis has not been confirmed and its exact role in the development of endometriosis remains unexplored. The upregulated expression of CFTR in female tract cancers and its interaction with $\mathrm{NF \kappa B}$, and the fact that UPAR is positively regulated by $\mathrm{NF} \kappa \mathrm{B}$ singling [15], led us to the hypothesis that CFTR might be involved in the progression of endometriosis by promoting NFKB and UPAR-dependent cell migration. To test this hypothesis, we thus undertook the present study to examine the expression and correlation of CFTR and UPAR in ovarian ectopic endometrioic samples and compared to normal endometria in human. The role of CFTR and its signaling involved in cell migration in a human endometrial cell line was also investigated.

\section{RESULTS}

\section{Significantly upregulated CFTR and uPAR expression in ovarian ectopic endometria}

We first evaluated the mRNA expression of CFTR in 46 of ovarian endometriotic lesions and 14 of normal endometria from the infertile patients without endometriosis. Quantitative real-time PCR (qPCR) results demonstrated that the expression of CFTR in endometriotic lesions was significantly higher than that in normal endometria (Figure 1A). In the remaining available samples, 21 endometriotic lesions and 10 normal endometria, we also examined the expression of UPAR and found significantly higher expression levels in endometriotic lesions compared to that of normal endometria (Figure 1B). Correlation analysis of both CFTR and uPAR in the same pool of samples revealed that the mRNA levels of CFTR were positively correlated with UPAR expression levels (Figure 1C, $\mathrm{r}=0.6640$, ***, $p<0.001)$. Consistent with mRNA expression, the protein levels of CFTR and UPAR were significantly increased in the ovarian endometriotic lesions (Figure 1D and 1E).

\section{CFTR expression regulates the migration of ISK cells}

Next, we investigated whether endometrial cell migration may be affected by the levels of CFTR expression. We first performed migration assay in ISK cells treated with a CFTR inhibitor (inh172). Surprisingly, the migration rate was not changed in the inh172 treated group in comparison to that in blank and DMSO control (Supplementary Figure 1). Given that ISK is cancer origin, we further examined the effect of CFTR inhibition on migration in primary culture of mouse endometrial epithelial cells and observed similar results showing insignificant effect with CFTR inhibition (Supplementary Figure 1), suggesting that the ion channel function of CFTR might not be involved in the regulation of cell migration in endometrial cells. Therefore, we further examined the migration ability in ISK cells with CFTR overexpression or knockdown using transwell migration assay. As shown in Figure 2A, overexpression of CFTR resulted in enhanced cell migration after 48hour incubation compared to that of the vector control. As expected, knockdown of CFTR led to reduced cell migration compared to that of the negative control (Figure 2B). These results suggest that CFTR expression levels, but not its channel activity, are tightly coupled to the migratory potential of endometrial cells.

\section{Overexpression of CFTR increases cell migration through activation of NFKB and UPAR signaling}

Given the presently observed correlation of CFTR and UPAR expression in human endometriosis and the 
well-established role of uPAR in cell invasion/migration $[36,37]$ and its regulation by $\mathrm{NF \kappa B}[15]$, we explored the involvement of $\mathrm{NF} \kappa \mathrm{B}$ in mediating the effect of CFTR on uPAR expression and cell migration. We overexpressed CFTR in ISK cells, and as expected, the expression levels of both NFkB p65 and uPAR were significantly increased in the CFTR-overexpressing ISK cells (Figure 3A and $3 \mathrm{~B})$. We also examined NFKB expression levels in some of the human endometriotic tissues $(n=20)$, which exhibited high levels of CFTR and UPAR (Figure 1), and detected significantly higher levels of $\mathrm{NF} \kappa \mathrm{B}$ expression compared to the normal control $(n=6)$, consistent with the finding from ISK cells (Figure 3C). Furthermore, the migration of the CFTR-overexpressing ISK cells was significantly inhibited when treated with $\mathrm{NF} \kappa \mathrm{B}$ inhibitor Curcumin $(10 \mu \mathrm{M})$ or Bay $(2 \mu \mathrm{M})$ (Figure $4 \mathrm{~A}$ and $4 \mathrm{~B})$. Western blot results showed that both curcumin and Bay treatment significantly reduced the expression of UPAR in CFTR overexpressing ISK cells (Figure 4C and 4D), indicating the involvement of NFKB in mediating the CFTR effect on uPAR expression, and thus cell migration.

\section{DISCUSSION}

This is the first quantitated expression study of CFTR in human endometriotic tissues and functional study in human endometrial cells establishing the important role of CFTR in cell migration. A strongly positive correlation between CFTR and UPAR is found in ovarian ectopic endometriosis, suggesting a link between CFTR and uPAR. The CFTR effect on UPAR expression is demonstrated to be mediated by NFkB. While uPAR has been shown to be regulated by $\mathrm{NF} \kappa \mathrm{B}$ in various cancers $[15,38]$, this study is the first to demonstrate the involvement of NFKB in the regulation of UPAR expression by CFTR in human endometrial cells since NFKB inhibitors can reverse the
A

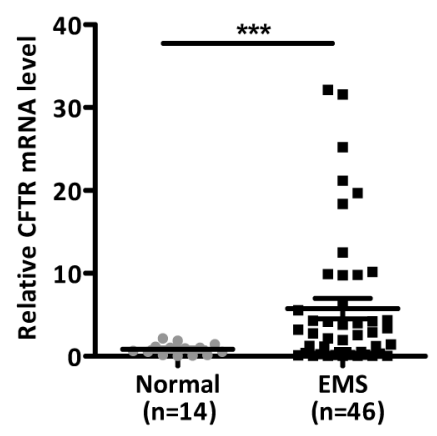

B

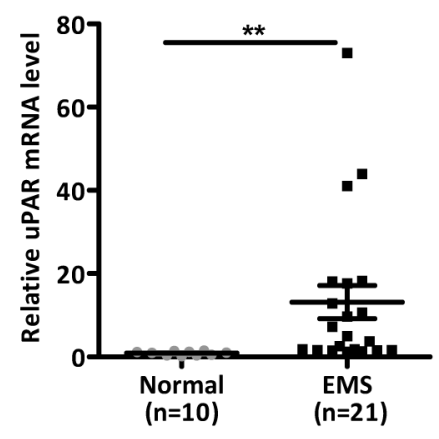

C

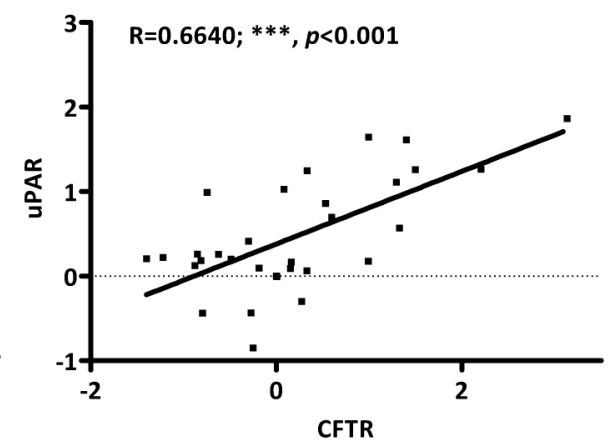

D
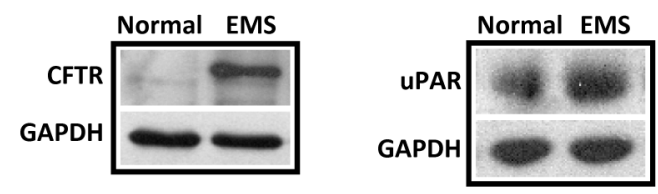

E
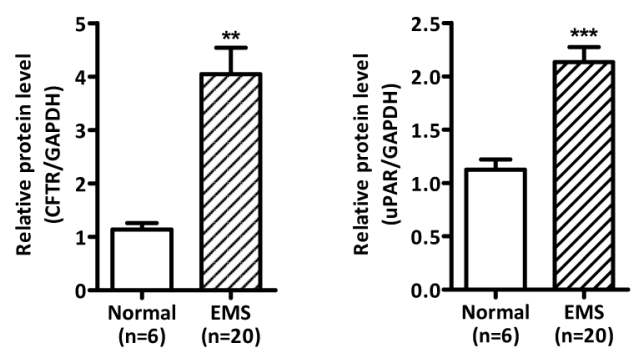

Figure 1: Abnormally high expression levels and strong correlation of CFTR and uPAR in human ovarian ectopic endometriotic tissues. (A) mRNA level of CFTR in human ectopic endometrium (EMS, $\mathrm{n}=46$ ) and normal endometrium from women without EMS (Normal, $\mathrm{n}=14$ ) was determined by qPCR. $* * *, p<0.001$, t-test. (B) qPCR results of uPAR expression in remaining available human ectopic endometria (EMS, $\mathrm{n}=21$ ) and normal endometria from women without EMS (Normal, $\mathrm{n}=10)$. ** $p<0.01$. (C) Correlation analysis between CFTR and uPAR in both CFTR and UPAR checked samples. The expression levels of uPAR are positively correlated with the CFTR expression levels in human endometriotic tissues with the $\mathrm{r}=0.6640(* * *, p<0.001)$. (D) Representive western blot showing protein expressions of CFTR and UPAR in EMS and normal endometria. GAPDH was used as the loading control. (E) Statistical analysis of CFTR and uPAR protein levels in EMS $(\mathrm{n}=20)$ compared to normal endometrium $(\mathrm{n}=6) . * *, p<0.01, * * *, p<$ 0.001. Values represent mean $\pm \mathrm{SEM}$. 
A
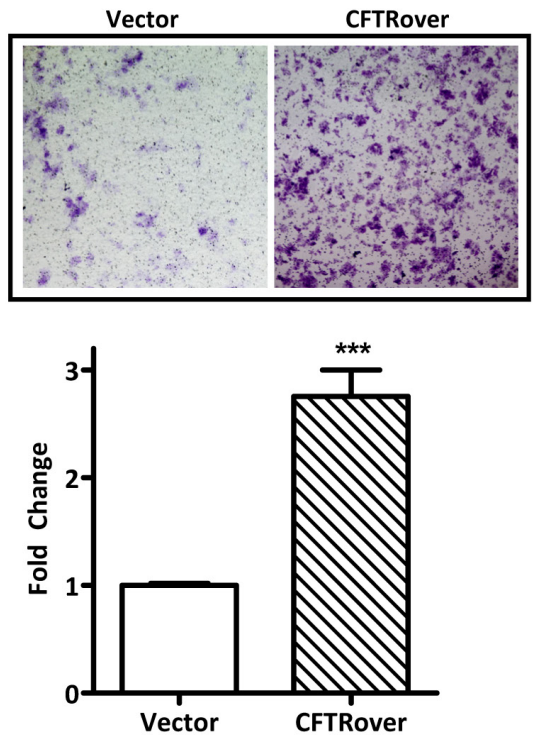

B
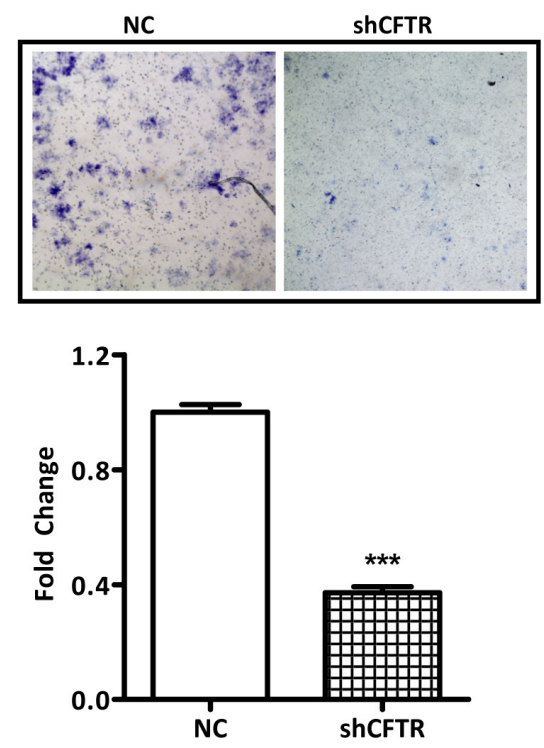

Figure 2: CFTR promotes migration of ISK cells. (A) Cells transfected with full-length CFTR plasmid (CFTRover) significantly increased cell migration compared with vector control group (Vector) in the transwell migration assay, $* * *, p<0.001$. (B) Cells infected with CFTR shRNA (shCFTR) suppressed cell migration compared with control group (NC), ${ }^{* * *}, p<0.001$. The experiments were repeated for 3 times. Values represent mean $\pm \mathrm{SEM}$.

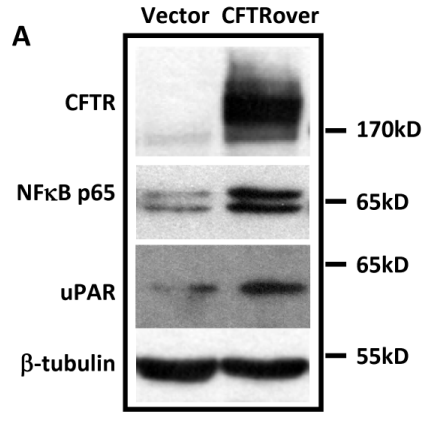

B

C
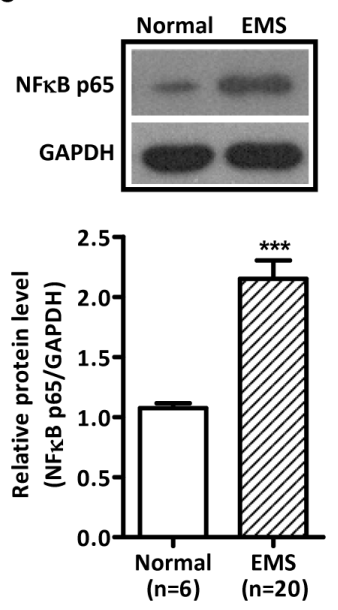
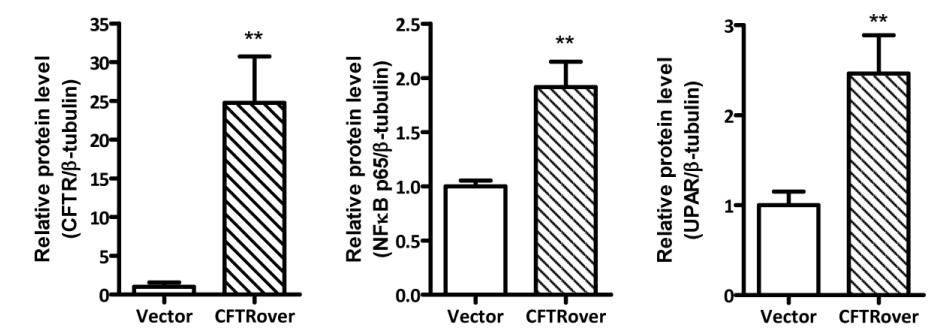

Figure 3: Effect of CFTR overexpression on NFкB p65 and uPAR expression in ISK cells. (A) Western blot analysis of upregulation of NFkB p65 and uPAR in CFTR-overexpressing ISK cells. (B) The corresponding statistical analysis (**, $p<0.01 v s$ vector control), the experiments were repeated 6 times. Values represent the mean \pm SEM. (C) Western blot analysis of NFkB p65 in human ectopic endometrium $(\mathrm{n}=20)$ and normal endometrium $(\mathrm{n}=6)$. ${ }^{* * *}, p<0.001, \mathrm{t}$-test. Values represent mean $\pm \mathrm{SEM}$. 
CFTR overexpression-induced upregulation of uPAR. Thus, the upregulated CFTR appears to result in abnormally high expression of uPAR through $\mathrm{NF \kappa B}$, and this explains the strongly positive correlation between CFTR and UPAR observed in the human endometriotic tissues. It should be noted that our previous studies have also observed a link between CFTR and UPAR in prostate cancer and non-small cell lung cancer $[16,30]$, however, CFTR was found to suppress UPAR in the cancer tissues in contrast to a positive correlation with uPAR observed in the present study. The CFTR-dependent signaling pathways involved in the cancers studied and endometriosis appear to be different.

The present study has demonstrated the involvement of NFKB in mediating the effect of CFTR in endometrial cells. A link between CFTR and NFkB is well documented although the exact relationship remains obscure and controversial. An inverse relationship between the two is well established in $\mathrm{CF}$, where chronic inflammation in the lung, a hallmark of the disease, is attributed to the upregulation of NFאB due to CFTR mutations [39, 40]. The inverse relationship between CFTR and NFkB has also been found in male reproductive tract, where high temperaturedownregulated CFTR with upregulated NFאB/COX2/PGE2 was found to be responsible for impaired testis-blood barrier, and thus disrupted spermatogenesis as seen in cryptorchidism [41]. However, a positive link between CFTR and NFאB has been found in the embryo [27] and cervical cancer [33]. Our present results have also demonstrated a positive relationship between CFTR and NFאB in ISK cells (Figure 3). Similar to the finding from previous reports $[27,33]$, the present study
A

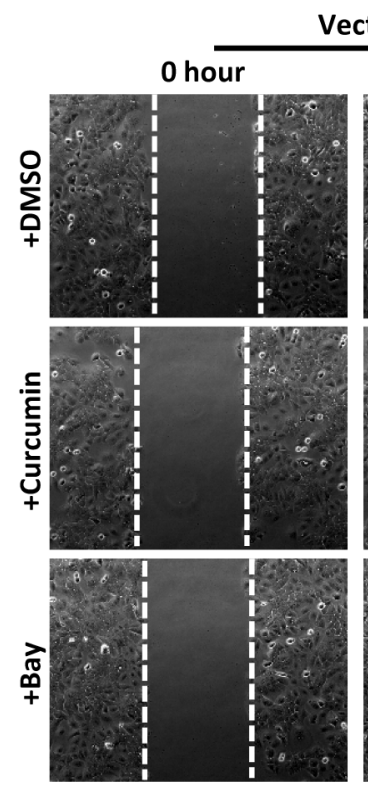

Vector

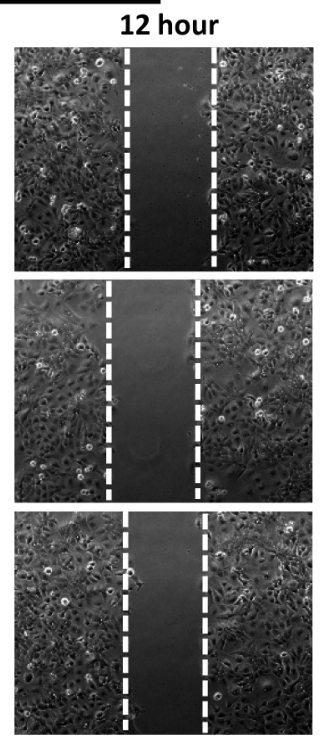

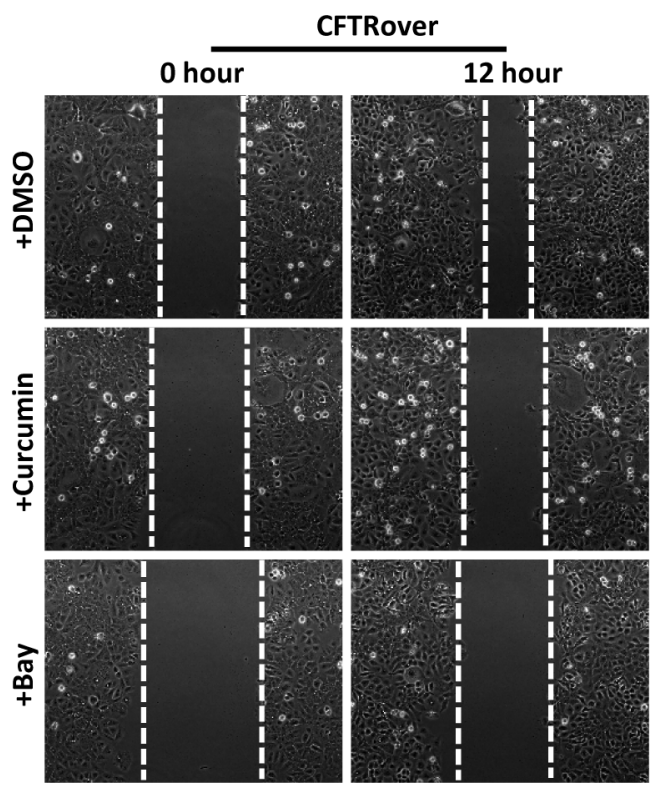

B

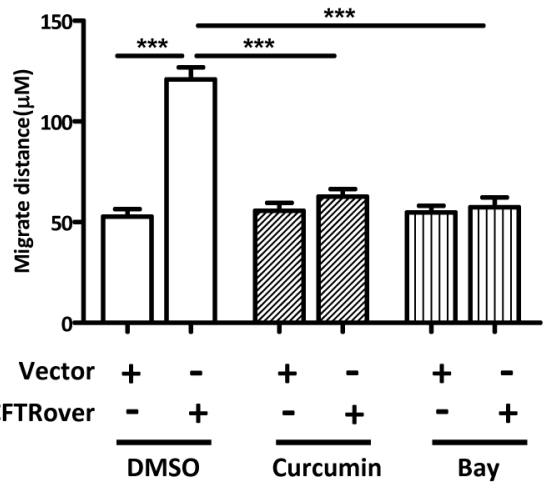

C

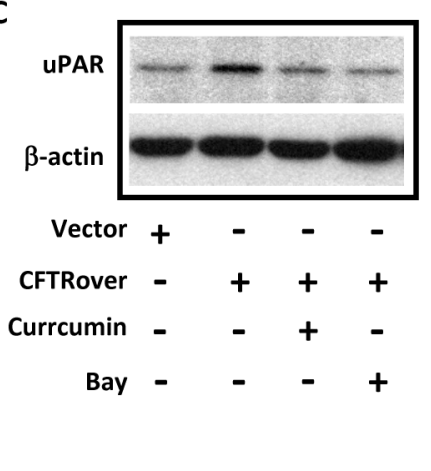

D

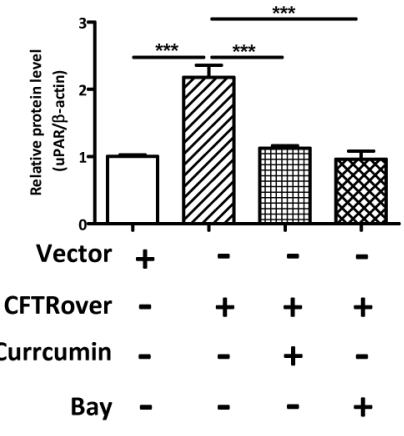

Figure 4: NFкB inhibitors reduce cell migration and uPAR expression in CFTR-overexpressing ISK cells. (A) Representative images of treated and untreated CFTR-overexpressing ISK cells are presented ( $\times 10$ magnification). ISK cells transfected with vector control or full-length CFTR were treated with NFאB inhibitors curcumin $(10 \mu \mathrm{M})$ or Bay $(2 \mu \mathrm{M})$ for 24 hours. (B) Statistical analysis of migration ability of ISK cells. Values represent the mean \pm SEM (***, $p<0.001 v s$ DMSO). (C) Western blot analysis of uPAR treated with NFאB inhibitors curcumin $(10 \mu \mathrm{M})$ or Bay $(2 \mu \mathrm{M})$ in CFTR-overexpressed ISK cells. (D) The corresponding statistical analysis $(* * *, p<0.001)$, the experiments were repeated 3 times. Values represent the mean $\pm \mathrm{SEM}$. 
also detected upregulated NFאB in the human endometriotic lesions exhibiting high levels of CFTR and UPAR, confirming a positive relationship between CFTR and NFkB in endometriosis. Taken together, it appears that CFTR may positively or negatively regulate $\mathrm{NF} \kappa \mathrm{B}$, depending on cellular contexts. The detail mechanism underlying the cell type-specific regulation of NFkB by CFTR awaits further investigation.

The present study has also demonstrated a functional role of CFTR in endometrial cell migration. Interestingly, the CFTR-regulated cell migration is not dependent on its ion channel function but its expression level. This suggests that CFTR does not merely function as an ion channel. As a membrane protein, CFTR has been shown to interact with quite a number of proteins [29, 42, 43], which may be independent of its channel function. The present results indicate that aberrantly high expression of CFTR, but not its channel function, and abnormally high UPAR expression confer a propensity of exaggerating cell migration that leads to the progression of endometriosis. Although the exact mechanism underlying the regulatory effect of CFTR on UPAR awaits further investigation, the present finding offers a potential diagnostic strategy for endometriosis targeting both CFTR and UPAR.

Human endometriosis is considered an estrogendependent disorder [44, 45] and the currently offered clinical treatments include surgical and hormonal treatments to alleviate pain and infertility [46, 47]. The presently demonstrated high expression of CFTR in ovarian ectopic endometriotic tissues can be explained by the well-established expression regulation of CFTR by estrogen $[23,48]$. The demonstrated role of CFTR in cell migration, together with dependence of CFTR expression on estrogen, provides a novel insight into the pathogenesis of endometriosis. In other words, the pathological progression of endometriosis may be triggered by abnormal estrogen-stimulated CFTR expression in the endometrium. The present findings also provide a rationale for the current treatment strategies for endometriosis. Hormonal treatments, such as hormonal contraceptives, are in place mostly for their anti-estrogen effects [45, 47], which are known to downregulate CFTR. Previous studies have shown that CFTR is cyclically expressed in mouse uterus [49], upregulated by estrogen [23] and downregulated progesterone [24]. Therefore, the clinically offered hormonal treatments for endometriosis could be mediated by the hormonal effect on CFTR downregulation. This is consistent with the important role of CFTR in cell migration and thus progression of endometriosis demonstrated in the present study. It should be noted that hormonal treatments have limitations for their side effects $[47,50]$. The present finding, therefore, suggests that targeting CFTR or its signaling (such as NFאB and uPAR) may be attractive alternatives for the intervention of endometriosis. The present findings warrant future investigation of diagnostic and treatment strategies for endometriosis targeting CFTR and related signaling.

\section{MATERIALS AND METHODS}

\section{Human tissue collection}

Forty-six women with endometriosis and fourteen women without endometriosis but infertility were recruited to the present study according to the previous criteria [51]. Endometriotic tissues were collected from the walls of endometriomas in patients with ovarian ectopic endometrium, and normal endometrial tissues (confirmed by pathologic diagnosis) were collected from normal endometrium by curettage in patients with infertility. All tissues were taken at the proliferative phase of the menstrual cycle.

\section{Ethical approval}

All samples were collected with informed consent from each patient and approval from the ethics committee of the Second People's hospital of Shenzhen (201306015) in China.

\section{Cell culture, gene overexpression and knockdown}

Primary mouse uterine epithelial cells were isolated and cultured as previously described [52]. Human endometrial Ishikawa cells (ISK), a highly differentiated endometrial epithelial adenocarcinoma cell and widely used in the studies of endometriosis [53-55], was cultured in Roswell Park Memorial Institute (RPMI)1640 supplemented with 10\% FBS and 1\% PenicillinStreptomycin in $5 \% \mathrm{CO}_{2}$ incubators at $37^{\circ} \mathrm{C}$. The pEGFP plasmid expressing wild-type CFTR (pEGFP-CFTR) was kindly provided by Professor Tzyh-Chang Hwang (University of Missouri-Columbia). For overexpression of CFTR, ISK cells were seeded in 6-well plates at $4 \times$ $10^{5}$ cells/well. $2.5 \mu \mathrm{g}$ of pEGFP-CFTR or pEGFP were transfected using $6 \mu \mathrm{l}$ Lipofectamine 2000 (Invitrogen, USA) following the manufacturer's instructions. For CFTR knockdown, lenti-virus (LV3) packaged shRNAs-targeting human CFTR (5'-GAA GTA GTG ATG GAG AAT GTA3') or scrambled noncoding shRNAs (5'-TTC TCC GAA CGT GTC ACG TTT-3') were purchased from GenePharma (Shanghai, China). The viruses $\left(1 \times 10^{9} \mathrm{TU} / \mathrm{ml}\right)$ were transduced into ISK cells with polybrene $(5 \mu \mathrm{g} / \mathrm{ml})$. Cells were cultured in the presence of puromycin $(5 \mu \mathrm{g} / \mathrm{ml})$ for three passages to select stable clones before migration assay.

\section{RNA isolation, reverse transcription, and quantitative real-time PCR}

Total RNA was extracted from human samples and cells by Trizol reagent (Invitrogen, USA) according to the instructions. Complementary DNA (cDNA) was synthesized from $1 \mu \mathrm{g}$ RNA with iScript cDNA synthesis kit (Bio-Rad, USA). For quantitative PCR, assays 
were performed in triplicate on an Applied Biosystems 7500Fast Real-Time PCR System with Taqman primers of CFTR (Hs00357004_m1) and uPAR (Hs00182181_m1) purchased from Applied Biosystems (USA).

\section{Western blot}

Human samples and ISK cells were lysated in a lysis buffer (RAPI buffer: $50 \mathrm{mM}$ Tris-HCl, pH8.0, 150 $\mathrm{mM} \mathrm{NaCl}, 1 \%$ NP-40, 0.5\% Sodium deoxycholate, $0.1 \%$ SDS). Western blot analysis was performed as described in our previous study [56]. Equal amounts of protein were subjected to $8 \%$ SDS-PAGE and were transferred onto nitrocellulose membranes. The transferred membrane was blocked with $5 \%$ skim milk in TBST $(50 \mathrm{mM}$ Tris-HCl, $150 \mathrm{mM} \mathrm{NaCl}$, and $0.05 \%$ Tween 20, $\mathrm{pH}$ 8.0) for $1 \mathrm{~h}$. The membrane was then incubated with the primary antibody in TBST plus $2 \%$ fat-free milk at $4^{\circ} \mathrm{C}$ for overnight. Antibodies used in this study were: Anti-CFTR (Almone Lab, catalog No.: ACL-006, 1:500), anti-uPAR (Santa Cruz, catalog No.: sc-10815, 1:500), anti-NFkB p65 (Cell signaling, catalog No.: 9496, 1:500), anti-GAPDH (Santa Cruz, catalog No.: sc-47724, 1:5000), anti- $\beta$-tubulin (Santa Cruz, catalog No.: sc-9104, 1:2000), anti- $\beta$-actin (Sigma, catalog No.: A2066, 1:5000). The membrane was subsequently washed with TBST and incubated for 1 hour with peroxidase-conjugated secondary antibody. The membrane was washed 3 times with TBST and then detected by chemiluminescence (Amersham, Piscataway, NJ).

\section{Migration assay}

Migration assay was used to assess the effect of CFTR on migration. Two different migration assays were performed in the present study. Briefly, the transwell migration assay was carried out in transwell champers with $8 \mu \mathrm{m}$ Pore Polycarbonate Membrane Inserts (Corning Incorporated, MA, USA). A total of $4 \times 10^{4}$ cells were seeded into the upper compartment of the transwell chambers in RPMI-1640 medium without FBS. Medium plus $20 \%$ FBS (600 $\mu \mathrm{l} /$ chamber) was added to the lower compartment. After 48-hour incubation, the cells in the upper side of the chambers were removed using tissue paper, then the migrated cells attached to the lower surface of the filter were fixed with 4\% PFA, stained with $0.5 \%$ crystal violet solution (w/v), and photographed under a phase contrast microscope and then counted cells in 5 randomly selected microscopic fields for statistical analysis.

For the wound healing migration assay, $5 \times 10^{5}$ cells were cultured in a 6-well plate and scratched with a $10 \mu \mathrm{l}$ culture tip in the fresh medium (RPMI-1640+1\% FBS) with or without NF $\kappa$ B signaling inhibitor curcumin (Sigma, catalog No.: C1386, USA) or Bay (Cayman, catalog No.:10010266, USA). The closure of the wound via the migration of cells into the wound was tracked and recorded using a live imaging system (Carl Zeiss, Jena, Germany) at 1 hour intervals for 24 hours. Cell migration was determined by measuring distances between parallel lines of cells. At least five imaging views were calculated on each well to quantify the migration rates.

\section{Statistical analysis}

All morphometric data were collected blindly. The results are shown as mean \pm S.E.M. Statistical significance for comparison between two measurements was determined by t test. One or two-way ANOVA was used for evaluation of the 3 or more measurements. Correlation analysis was carried out using Pearson's correlation for normally distributed data. All statistical analyses were performed using Prism 6.0 (GraphPad Prism). Differences were considered to be statistically significant at $p<0.05$.

\section{Author contributions}

H.C.C. conceptualized. H.C.C., H.C. and W.Q.H. designed. W.Q.H., C.H., J.T.Z., Q.C.W. A.H.J. and L.L.T. were involved in the experimentation and data analysis. A.H.J., Z.M.C and X.P.Z. collected human samples. C.H. and W.Q.H. wrote the manuscript, and H.C.C. revised. All authors gave their final approval of the version to be published.

\section{ACKNOWLEDGMENTS}

The work was supported in parts by National Basic Research Program of China (2013CB967404, 2013CB967403), National Natural Science Foundation of China (No. 81671432 and 81370709), RGC of Hong Kong (GRF 461213), Science and Technology Planning Project of Guangdong Province (2016A020218005), Fund for high level medical discipline construction of Shenzhen (2016031638), and the Focused Investment Scheme of the Chinese University of Hong Kong.

We are grateful to the women who gave informed consent for the use of their material in this study.

\section{CONFLICTS OF INTEREST}

The authors declare no conflicts of interest.

\section{REFERENCES}

1. Giudice LC, Kao LC. Endometriosis. Lancet. 2004; 364:1789-1799.

2. Eskenazi B, Warner ML. Epidemiology of endometriosis. Obstet Gynecol Clin North Am. 1997; 24:235-258.

3. Giudice LC. Clinical practice. Endometriosis. N Engl J Med. 2010; 362:2389-2398.

4. Greaves E, Collins F, Esnal-Zufiaurre A, Giakoumelou S, Horne AW, Saunders PT. Estrogen receptor (ER) agonists differentially regulate neuroangiogenesis in 
peritoneal endometriosis via the repellent factor SLIT3. Endocrinology. 2014; 155:4015-4026.

5. Kobayashi H. Invasive capacity of heterotopic endometrium. Gynecol Obstet Invest. 2000; 50:26-32.

6. Gaetje R, Kotzian S, Herrmann G, Baumann R, StarzinskiPowitz A. Invasiveness of endometriotic cells in vitro. Lancet. 1995; 346:1463-1464.

7. Fuhrman B. The urokinase system in the pathogenesis of atherosclerosis. Atherosclerosis. 2012; 222:8-14.

8. McMahon BJ, Kwaan HC. Components of the plasminogenplasmin system as biologic markers for cancer. Adv Exp Med Biol. 2015; 867:145-156.

9. Noh H, Hong S, Huang S. Role of urokinase receptor in tumor progression and development. Theranostics. 2013; 3:487-495.

10. Littlefield BA. Plasminogen activators in endometrial physiology and embryo implantation: a review. Ann N Y Acad Sci. 1991; 622:167-175.

11. Tabibzadeh S. The signals and molecular pathways involved in human menstruation, a unique process of tissue destruction and remodelling. Mol Hum Reprod. 1996; 2:77-92.

12. Casslen B, Nordengren J, Gustavsson B, Nilbert M, Lund LR. Progesterone stimulates degradation of urokinase plasminogen activator (u-PA) in endometrial stromal cells by increasing its inhibitor and surface expression of the u-PA receptor. J Clin Endocrinol Metab. 1995; 80:2776-2784.

13. Ramon L, Gilabert-Estelles J, Castello R, Gilabert J, Espana F, Romeu A, Chirivella M, Aznar J, Estelles A. mRNA analysis of several components of the plasminogen activator and matrix metalloproteinase systems in endometriosis using a real-time quantitative RT-PCR assay. Hum Reprod. 2005; 20:272-278.

14. Sillem M, Prifti S, Monga B, Buvari P, Shamia U, Runnebaum B. Soluble urokinase-type plasminogen activator receptor is over-expressed in uterine endometrium from women with endometriosis. Mol Hum Reprod. 1997; 3:1101-1105.

15. Wang Y, Dang J, Wang H, Allgayer H, Murrell GA, Boyd D. Identification of a novel nuclear factor- $\kappa \mathrm{B}$ sequence involved in expression of urokinase-type plasminogen activator receptor. Eur J Biochem. 2000; 267:3248-3254.

16. Xie C, Jiang XH, Zhang JT, Sun TT, Dong JD, Sanders AJ, Diao RY, Wang Y, Fok KL, Tsang LL, Yu MK, Zhang $\mathrm{XH}$, Chung YW, et al. CFTR suppresses tumor progression through miR-193b targeting urokinase plasminogen activator (uPA) in prostate cancer. Oncogene. 2013; 32:2282-2291, 2291.e1-7.

17. Couzin-Frankel J. Genetics. The promise of a cure: 20 years and counting. Science. 2009; 324:1504-1507.

18. Collins FS. Cystic fibrosis: molecular biology and therapeutic implications. Science. 1992; 256:774-779.
19. Harris A, Argent BE. The cystic fibrosis gene and its product CFTR. Semin Cell Biol. 1993; 4:37-44.

20. Chan HC, Chen H, Ruan Y, Sun T. Physiology and pathophysiology of the epithelial barrier of the female reproductive tract: role of ion channels. Adv Exp Med Biol. 2012; 763:193-217.

21. Ruan YC, Chen $\mathrm{H}$, Chan HC. Ion channels in the endometrium: regulation of endometrial receptivity and embryo implantation. Hum Reprod Update. 2014; 20:517-529.

22. Mularoni A, Adessi GL, Arbez-Gindre F, Agnani G, Nicollier M. Competitive RT-PCR to quantify CFTR mRNA in human endometrium. Clin Chem. 1996; 42:1765-1769.

23. Rochwerger L, Dho S, Parker L, Foskett JK, Buchwald M. Estrogen-dependent expression of the cystic fibrosis transmembrane regulator gene in a novel uterine epithelial cell line. J Cell Sci. 1994; 107:2439-2448.

24. Mularoni A, Beck L, Sadir R, Adessi GL, Nicollier M. Down-regulation by progesterone of CFTR expression in endometrial epithelial cells: a study by competitive RT-PCR. Biochem Biophys Res Commun. 1995; 217:1105-1111.

25. Chan HC, Ruan YC, He Q, Chen MH, Chen H, Xu WM, Chen WY, Xie C, Zhang XH, Zhou Z. The cystic fibrosis transmembrane conductance regulator in reproductive health and disease. J Physiol. 2009; 587:2187-2195.

26. Yu J, Xiao F, Zhang Q, Liu B, Guo Y, Lv Z, Xia T, Chen S, Li K, Du Y, Guo F. PRLR regulates hepatic insulin sensitivity in mice via STAT5. Diabetes. 2013; 62:3103-3113.

27. Lu YC, Chen H, Fok KL, Tsang LL, Yu MK, Zhang XH, Chen J, Jiang X, Chung YW, Ma AC, Leung AY, Huang HF, Chan HC. CFTR mediates bicarbonate-dependent activation of miR-125b in preimplantation embryo development. Cell Res. 2012; 22:1453-1466.

28. Marino GI, Kotsias BA. Cystic fibrosis transmembrane regulator (CFTR) in human trophoblast BeWo cells and its relation to cell migration. Placenta. 2014; 35:92-98.

29. Sun TT, Wang Y, Cheng H, Xiao HZ, Xiang JJ, Zhang JT, Yu SB, Martin TA, Ye L, Tsang LL, Jiang WG, Xiaohua J, Chan HC. Disrupted interaction between CFTR and AF-6/ afadin aggravates malignant phenotypes of colon cancer. Biochim Biophys Acta. 2014; 1843:618-628.

30. Li J, Zhang JT, Jiang X, Shi X, Shen J, Feng F, Chen J, Liu G, He P, Jiang J, Tsang LL, Wang Y, Rosell R. The cystic fibrosis transmembrane conductance regulator as a biomarker in non-small cell lung cancer. Int J Oncol. 2015; 46:2107-2115.

31. Xu J, Yong M, Li J, Dong X, Yu T, Fu X, Hu L. High level of CFTR expression is associated with tumor aggression and knockdown of CFTR suppresses proliferation of ovarian cancer in vitro and in vivo. Oncol Rep. 2015; 33:2227-2234.

32. Peng X, Wu Z, Yu L, Li J, Xu W, Chan HC, Zhang Y, $\mathrm{Hu}$ L. Overexpression of cystic fibrosis transmembrane 
conductance regulator (CFTR) is associated with human cervical cancer malignancy, progression and prognosis. Gynecol Oncol. 2012; 125:470-476.

33. Wu Z, Peng X, Li J, Zhang Y, Hu L. Constitutive activation of nuclear factor $\kappa \mathrm{B}$ contributes to cystic fibrosis transmembrane conductance regulator expression and promotes human cervical cancer progression and poor prognosis. Int J Gynecol Cancer. 2013; 23:906-915

34. Liu K, Zhang X, Zhang JT, Tsang LL, Jiang X, Chan HC. Defective CFTR- $\beta$-catenin interaction promotes NF- $\mathrm{B}$ nuclear translocation and intestinal inflammation in cystic fibrosis. Oncotarget. 2016; 7:64030-64042. doi: 10.18632/ oncotarget. 11747.

35. Stephens AN, Hannan NJ, Rainczuk A, Meehan KL, Chen J, Nicholls PK, Rombauts LJ, Stanton PG, Robertson DM, Salamonsen LA. Post-translational modifications and protein-specific isoforms in endometriosis revealed by $2 \mathrm{D}$ DIGE. J Proteome Res. 2010; 9:2438-2449.

36. Asuthkar S, Gondi CS, Nalla AK, Velpula KK, Gorantla $\mathrm{B}$, Rao JS. Urokinase-type plasminogen activator receptor (uPAR)-mediated regulation of WNT/ $\beta$-catenin signaling is enhanced in irradiated medulloblastoma cells. J Biol Chem. 2012; 287:20576-20589.

37. Smith HW, Marshall CJ. Regulation of cell signalling by uPAR. Nat Rev Mol Cell Biol. 2010; 11:23-36.

38. Moreau M, Mourah S, Dosquet C. $\beta$-Catenin and NF- $\kappa B$ cooperate to regulate the $\mathrm{UPA} / \mathrm{uPAR}$ system in cancer cells. Int J Cancer. 2011; 128:1280-1292.

39. Chen J, Jiang XH, Chen $\mathrm{H}$, Guo JH, Tsang LL, Yu $\mathrm{MK}, \mathrm{Xu}$ WM, Chan HC. CFTR negatively regulates cyclooxygenase-2-PGE(2) positive feedback loop in inflammation. J Cell Physiol. 2012; 227:2759-2766.

40. Knorre A, Wagner M, Schaefer HE, Colledge WH, Pahl HL. DeltaF508-CFTR causes constitutive NF-kappaB activation through an ER-overload response in cystic fibrosis lungs. Biol Chem. 2002; 383:271-282.

41. Chen J, Fok KL, Chen H, Zhang XH, Xu WM, Chan HC. Cryptorchidism-induced CFTR down-regulation results in disruption of testicular tight junctions through up-regulation of NF-кB/COX-2/PGE2. Hum Reprod. 2012; 27:2585-2597.

42. Ruan YC, Wang Y, Da Silva N, Kim B, Diao RY, Hill E, Brown D, Chan HC, Breton S. CFTR interacts with $\mathrm{ZO}-1$ to regulate tight junction assembly and epithelial differentiation through the ZONAB pathway. J Cell Sci. 2014; 127:4396-4408.

43. Cheng J, Wang H, Guggino WB. Modulation of mature cystic fibrosis transmembrane regulator protein by the PDZ domain protein CAL. J Biol Chem. 2004; 279:1892-1898.

44. Garai J, Molnar V, Varga T, Koppan M, Torok A, Bodis J. Endometriosis: harmful survival of an ectopic tissue. Front Biosci. 2006; 11:595-619.
45. Kitawaki J, Kado N, Ishihara H, Koshiba H, Kitaoka Y, Honjo H. Endometriosis: the pathophysiology as an estrogen-dependent disease. J Steroid Biochem Mol Biol. 2002; 83:149-155.

46. Abbott JA, Hawe J, Clayton RD, Garry R. The effects and effectiveness of laparoscopic excision of endometriosis: a prospective study with 2-5 year follow-up. Hum Reprod. 2003; 18:1922-1927.

47. Dunselman GA, Vermeulen N, Becker C, Calhaz-Jorge C, D'Hooghe T, De Bie B, Heikinheimo O, Horne AW, Kiesel L, Nap A, Prentice A, Saridogan E, Soriano D, Nelen W. European Society of Human Reproduction and Embryology ESHRE guideline: management of women with endometriosis. Hum Reprod. 2014; 29:400-412.

48. Tsang LL, Chan LN, Liu CQ, Chan HC. Effect of phenol red and steroid hormones on cystic fibrosis transmembrane conductance regulator in mouse endometrial epithelial cells. Cell Biol Int. 2001; 25:1021-1024.

49. Chan LN, Tsang LL, Rowlands DK, Rochelle LG, Boucher $\mathrm{RC}$, Liu CQ, Chan HC. Distribution and regulation of ENaC subunit and CFTR mRNA expression in murine female reproductive tract. J Membr Biol. 2002; 185:165-176.

50. Lindsay SF, Luciano DE, Luciano AA. Emerging therapy for endometriosis. Expert Opin Emerg Drugs. 2015; 20:449-461.

51. Wang C, Jin A, Huang W, Tsang LL, Cai Z, Zhou X, Chen H, Chan HC. Up-regulation of Bcl-2 by CD147 through ERK activation results in abnormal cell survival in human endometriosis. J Clin Endocrinol Metab. 2015; 100:E955-963.

52. Chan LN, Wang XF, Tsang LL, Chan HC. Pyrimidinoceptors-mediated activation of $\mathrm{Ca}^{2+}$-dependent $\mathrm{Cl}^{-}$conductance in mouse endometrial epithelial cells. Biochim Biophys Acta. 2000; 1497:261-270.

53. Nishida $M$, Kasahara $K$, Kaneko $M$, Iwasaki $H$, Hayashi K. [Establishment of a new human endometrial adenocarcinoma cell line, Ishikawa cells, containing estrogen and progesterone receptors]. [Article in Japanese]. Nihon Sanka Fujinka Gakkai Zasshi. 1985; 37:1103-1111.

54. Guay S, Akoum A. Stable inhibition of interleukin 1 receptor type II in Ishikawa cells augments secretion of matrix metalloproteinases: possible role in endometriosis pathophysiology. Reproduction. 2007; 134:525-534.

55. Cho S, Mutlu L, Zhou Y, Taylor HS. Aromatase inhibitor regulates let-7 expression and let-7f-induced cell migration in endometrial cells from women with endometriosis. Fertil Steril. 2016; 106:673-680.

56. Chen MH, Chen H, Zhou Z, Ruan YC, Wong HY, Lu YC, Guo JH, Chung YW, Huang PB, Huang HF, Zhou WL, Chan $\mathrm{HC}$. Involvement of CFTR in oviductal HCO3- secretion and its effect on soluble adenylate cyclase-dependent early embryo development. Hum Reprod. 2010; 25:1744-1754. 